2007-01-01

\title{
Alternative Exon Usage Selectively Determines Both Tissue Distribution and Subcellular Localization of the acyl-CoA Thioesterase 7 Gene Products.
}

\author{
Mary Hunt \\ Biological Sciences, mary.hunt@tudublin.ie \\ Sinead Greene \\ Karolinska Institute \\ Kjell Hultenby \\ Karolinska Institute
}

See next page for additional authors

Follow this and additional works at: https://arrow.tudublin.ie/scschbioart

Part of the Molecular Genetics Commons

\section{Recommended Citation}

Hunt, M. et al. (2007) Alternative exon usage selectively determines both tissue distribution and subcellular localization of the acyl-CoA thioesterase 7 gene products. Cellular and Molecular Life Sciences (2007) 64: pp. 1558. doi:10.1007/s00018-007-7062-6

This Article is brought to you for free and open access by the School of Biological Sciences at ARROW@TU Dublin. It has been accepted for inclusion in Articles by an authorized administrator of ARROW@TU Dublin. For more information, please contact arrow.admin@tudublin.ie, aisling.coyne@tudublin.ie,gerard.connolly@tudublin.ie.

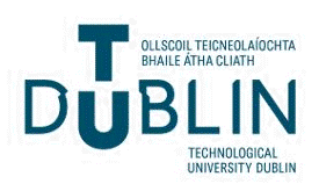


Authors

Mary Hunt, Sinead Greene, Kjell Hultenby, L. Thomas Svensson, Susanna Engberg, and Stefan E H Alexson 


\section{Alternative exon usage selectively determines both tissue distribution and subcellular localization of the acyl-CoA thioesterase 7 gene products.}

\section{Mary C. Hunt, Sinead Greene, §Kjell Hultenby, ${ }^{*}$ L. Thomas Svensson, **Susanna Engberg, and Stefan E. H. Alexson}

Karolinska Institutet, Department of Laboratory Medicine, Division of Clinical Chemistry C1-74, and §Division of Pathology, F-52, Karolinska University Hospital at Huddinge, SE-141 86 Stockholm, Sweden,

*Present address: Biovitrum AB, Arvid Wallgrens Backe, SE-413 46, Sweden.

**Astrazeneca R\&D Mölndal, SE-431 83 Mölndal, Sweden

Running title: Characterization of Acot7 thioesterases

Address for correspondence:

Dr. Stefan Alexson

Karolinska Institutet

Department of Laboratory Medicine

Division of Clinical Chemistry C1-74,

Karolinska University Hospital at Huddinge Phone: +46-8-58581274

SE-141 86 Stockholm

Fax: $+46-8-58581260$

Sweden

email: stefan.alexson@ki.se 


\section{Abstract}

Acyl-CoA thioesterases (ACOTs) catalyze the hydrolysis of acyl-CoAs to free fatty acids and coenzyme A. Recent studies have demonstrated that one gene named Acot7, reported to be mainly expressed in brain and testis, is transcribed in several different isoforms by alternative usage of first exons. Strongly decreased levels of ACOT7 activity and protein in both mitochondria and cytosol was reported in patients diagnosed with fatty acid oxidation defects, linking ACOT7 function to regulation of fatty acid oxidation in other tissues. In this study, we have identified five possible first exons in mouse Acot7 (Acot7a-e) and show that all five first exons are transcribed in a tissue specific manner. Taken together, these data show that the Acot7 gene is expressed as multiple isoforms in a tissue specific manner, and that expression in tissues other than brain and testis is likely to play important roles in fatty acid metabolism.

Key words: acyl-CoA thioesterase, brain, lipid metabolism, acyl-CoA hydrolase, acyl-CoA, testis. 


\section{INTRODUCTION}

Long-chain acyl-CoA thioesterases (EC 3.1.2.2) (ACOTs) are a group of enzymes that hydrolyze acyl-CoA esters to the free fatty acid and coenzyme A (CoASH). The importance of ACOT enzyme activity is evident on examination of the many different processes involving long chain acyl-CoA esters and free fatty acids. Long-chain acyl-CoA esters play a central role in the biosynthesis of lipids, and degradation of fatty acids via -oxidation. It is now also apparent that, apart from their use as an energy source, long chain acyl-CoA esters play important roles in many other cellular processes, as reviewed $(1,2)$. Therefore the regulation of acyl-CoA and free fatty acids is important in intracellular metabolism.

In view of the fact that ACOT enzymes hydrolyze acyl-CoAs to free fatty acids and $\mathrm{CoASH}$, we have speculated that they are functionally linked to lipid metabolism where they regulate intracellular levels of acyl-CoAs and free fatty acids. Several evolutionary unrelated enzymes and protein families of Acots have now been identified (for review see $(3,4)$ ). The peroxisome proliferatorinduced activity in mitochondria and cytosol is due to induction of two protein families (5-7), which were named Type-I and Type-II acyl-CoA thioesterases (8). The Type-II acyl-CoA thioesterases (now renamed Acot7 under a new nomenclature system recently introduced (9)) in cytosol was first identified by Miyazawa et al (5) and two of these isoforms were later cloned from rat $(10,11)$. These enzymes were shown to be inducible in liver and testis at both mRNA and protein level by treatment of rats with di-(2-ethylhexyl)phthalate (DEHP), a 
peroxisome proliferator. These enzymes were shown to have a broad substrate specificity, and could hydrolyze acyl-CoAs from $\mathrm{C}_{6}-\mathrm{C}_{22}$-CoA $(5,8,12,13)$. There is a very high sequence similarity between the rat, mouse and human ACOT7 sequences, suggesting an important evolutionary conservation of these genes. Brain and testis contain by far the highest ACOT activities, and since $75-90 \%$ of the activity in brain is due to ACOT7 (13), ACOT7 was also originally designated brain acyl-CoA hydrolase (BACH) (23). In human brain, ACOT7 is expressed in neurons, e.g pyramidal cells in the cerebral cortex and Purkinje cells in the cerebellum (14). In developing mouse brain, Acot7 was shown to be expressed during embryogenesis in association with neuronal differentiation (15), and in adult mouse brain ACOT7 is exclusively localized to neurons (16). Recently, the genomic structure of the Acot7 gene family was characterized in both human and mouse $(14,16)$. Although these works showed that several isoforms of Acot7 are generated from a single gene following alternative splicing of different first exons, with the resulting proteins being expressed mainly in brain and testis, the function of Acot7 is still unknown in these tissues. However, recently it was demonstrated that some patients diagnosed with fatty acid oxidation defects also has severely decreased ACOT7 expression in fibroblasts, suggesting that ACOT7 may also have important functions outside the brain and testis in regulation of fatty acid oxidation. Since there is almost no data available on the expression of Acot7 isoforms in tissues besides brain and testis, we here performed a careful expression analysis of Acot7. First we took a bioinformatics approach to characterize the gene encoding the ACOT7 protein family in mouse. Combined with expression profiling, real-time PCR and cellular localization experiments, we have now identified five alternative first exons encoding isoenzymes with 
different amino-terminal protein sequences that show different cellular localizations and distinct tissue expression patterns.

\section{Experimental procedures}

\section{Animals and treatments}

SV/129 male and female mice were maintained on a normal chow diet (R36, Lactamin, Vadstena, Sweden). All mice were euthanized by $\mathrm{CO}_{2}$ asphyxiation, followed by cervical dislocation. Various organs were removed and frozen in liquid nitrogen, and stored at $-70^{\circ} \mathrm{C}$ for preparation of total RNA. Ethical permission was held from the Animal Experimental Ethical Committee, Stockholm, for all animal experiments.

\section{Identification of cytosolic and mitochondrial Acot7}

A blastn sequence similarity search (17) was carried out against the entries in the mouse Expressed Sequence Tag (EST) database (http://www.ncbi.nlm.nih.gov) using the cDNA sequence for the human cytosolic acyl-CoA thioesterase (now Acot7_v1) (13) as a search template. Numerous hits were aligned to the search template and full-length sequences corresponding to mouse Acot7_v1 (previously called CTE-II or BACHa) were assembled using DNAStar Seqman software (DNAStar). Acot7_v1 sequences with different 5'-ends were aligned against the sequence in ENSEBML mouse genome database (http:/ / www.ensembl.org) to identify the corresponding alternative first exons. By this strategy, two EST clones with extended 5' ends (AA466273 and AA103190) were identified. These 
clones were purchased from UK HPMG Resource Centre (Hinxton, Cambridge, United Kingdom) and fully sequenced.

\section{Northern blot analysis}

Total RNA was prepared from the various organs using QuickPrep ${ }^{R}$ total RNA extraction kit (GE Healthcare, Uppsala, Sweden) or Ultraspec RNA kit (Biotecx Laboratories Inc, Houston, Texas), and Northern blot analysis was carried out as described previously (18) using a ${ }^{32} \mathrm{P}$-labeled full-length probe for mouse Acot7_v2 (previously called MTE-II or BACHb) cDNA. All blots were exposed to X-ray film at $-70^{\circ} \mathrm{C}$.

\section{Antibody preparation and Western blot analysis}

A peptide was synthesized based on the deduced amino acid sequence of the carboxy-terminal end of the Acot7_v1 (Acot7a) cDNA - CKAKRQGHTEPQP-OH (with a cysteine added at the amino-terminal end for coupling of the peptide), which will recognize all isoforms of the Acot7 gene family. Rabbits were immunized with $500 \mu \mathrm{g}$ of the peptide conjugated to Keyhole Limpet Hemocyanin, emulsified in Freund's complete adjuvant. Booster injections of 250 $\mu \mathrm{g}$ of the peptide-conjugate emulsified in Freund's incomplete adjuvant and bleedings were carried out according to standard protocols. Antibodies were affinity purified using a column with the peptide conjugated to Epoxy-activated Sepharose 6B (GE Healthcare, Uppsala, Sweden). Western blot analysis was carried out on $100 \mu \mathrm{g}$ of homogenate protein (homogenized in $20 \mathrm{mM}$ Tris- $\mathrm{HCl}$, $\mathrm{pH}$ 8.0) or $100 \mu \mathrm{g}$ of mitochondrial and cytosolic protein prepared from various 
male and female mouse tissues and separated on $12 \%$ sodium dodecylsulfate polyacrylamide gels (SDS-PAGE). Western blotting was performed by electrophoretic transfer of the separated proteins onto nitrocellulose filters (Nitropure, Micron Separations Inc., Westborough, MA) using a Transblot cell (BioRad Laboratories, Hercules, CA). The blots were probed with the antiACOT7a antibody and subsequently with horseradish peroxidase-conjugated secondary antibody and visualized by enhanced chemiluminenscence (ECL ${ }^{\mathrm{TM}}$, GE Healthcare) using X-ray film.

\section{Cell transfection and cellular localization experiments}

Oligonucleotides were designed based on the sequence of the full-length cDNA for mouse Acot7_v1 and Acot7_v2 for cloning of the open reading frames as fusion proteins with green fluorescent protein (GFP). The full-length cDNAs were amplified from mouse kidney $\left(A \cot 7 \_v 1\right)$ and brown adipose tissue (Acot7_v2) total RNA using One Step RNA PCR kit (AMV) (Takara Biomedicals). Primers used were as follows: 5' primers: Acot7_v1 (amplifies from methionine * in Fig. 1B): 5'-AAGATGTCCGGCCCCACCAC-3'; Acot7_v2: 5'ACAATGAAGCTGCTGGTCGGGACT-3' and the same 3' primer for both gene products: 5'-GGGGCTGAGGCTCTGTGTGGC-3'. Products were cloned into the pcDNA3.1/CT-GFP vector (Invitrogen), in-frame with the GFP at the carboxyterminal end. Sequence analysis was performed using Big Dye Terminator (ABI Prism, PE Biosystems) and was sequenced by Cybergene AB (Huddinge, Sweden). 
Human skin fibroblasts were grown in Eagles Minimum Essential Medium (Sigma, St. Louis, MO), supplemented with $10 \%$ fetal calf serum (Life Technologies), $100 \mathrm{U} / \mathrm{ml}$ penicillin and $100 \mathrm{Gg} / \mathrm{ml}$ streptomycin in an atmosphere of $5 \% \mathrm{CO}_{2}$. Approximately $1.6 \times 10^{6}$ cells were grown overnight in 60 $\mathrm{mm}$ dishes on glass cover-slips and were transfected with $10 \mu \mathrm{g}$ Acot7_v1/CTGFP and Acot7_v2/CT-GFP plasmids using the calcium phosphate method as described, but without staining of the nucleus with Hoesch 33342 (19). Briefly, transfected cells were grown for 48 hours, fixed, and permeabilized with Triton X-100. For mitochondrial localization, cells were preincubated for $30 \mathrm{mins}$ at $37^{\circ} \mathrm{C}$ with $100 \mathrm{nM}$ Mitotracker® Orange CMTMRos (Invitrogen Corp., CA, USA) before permeabilization and analyzed directly. For cytosolic localization, cells were incubated with a rabbit anti-GFP antibody (Molecular Probes, Leiden, The Netherlands) and subsequently a CY3 conjugated affinity pure donkey antirabbit IgG (Jackson ImmunoResearch). Cells were examined in Leica DM IRBE fluroescence microscope, using Hamamatsu C4742-95 camera and C4742-95 Twain Interface software.

\section{Quantitative Real-Time Polymerase Chain Reaction (Q-PCR)}

Total RNA was isolated from various organs from male SV/129 mice using Trizol reagent (Invitrogen Corp.). Total RNA was DNase1 treated (Promega Corp.) and pooled from three animals. cDNA synthesis was carried out on 1】g of pooled total RNA from each tissue, using iScript cDNA synthesis kit (Biorad). Quantitative-polymerase chain (Q-PCR) was performed in an ABI Prism 7000 
sequence detection system, using Power Sybrgreen Master Mix (Applied Biosystems). Primers were designed based on the cDNA sequences of the various gene products as outlined in Table I. An endogenous control of mouse hypoxanthine-guanine phosphoribosyl transferase (Hprt) was used. The Q-PCR was run in singleplex in triplicate for each sample. Data were analyzed using the ABI Prism 7000 SDS software, and the average $C_{T}$ value per triplicate was used to calculate the relative amounts of each mRNA transcript, using the $2^{-\mathrm{\square} C \mathrm{CT}}$ method.

\section{Immunoelectron microscopy}

Mice were fixed by perfusion with 3\% paraformaldehyde $+0.1 \%$ glutaraldehyde in $0.1 \mathrm{M}$ phosphate buffer $(\mathrm{PB}), \mathrm{pH}$ 7.4. Specimens were then rinsed in $0.1 \mathrm{M} \mathrm{PB}$, infiltrated with 2.3 M sucrose in $0.1 \mathrm{M} \mathrm{PB}$, placed on aluminum holders, and then frozen in liquid nitrogen. Sectioning was performed according to Tokuyasu (20) at $-95^{\circ} \mathrm{C}$. To block non-specific binding, the sections were placed on drops of $10 \%$ bovine serum albumin (BSA, fraction V, Sigma, St. Louis, MO/USA) in 0.1 M PB for $2 \mathrm{~h}$. Subsequently, the sections were incubated with the ACOT7a primary antibody diluted 1:100 in $0.1 \mathrm{M}$ PB containing $0.1 \%$ BSA (PBB) overnight in a humidified chamber at room temperature. Normal rabbit serum was used as control. The sections were thoroughly washed in PBB and bound antibodies were detected with protein A coated with $10 \mathrm{~nm}$ gold. The sections were then washed, fixed in $2 \%$ glutaraldehyde in $0.1 \mathrm{M}$ PB for $10 \mathrm{~min}$, washed in distilled water, and embedded in $2 \%$ methyl cellulose containing $0.1 \%$ uranyl acetate (21). The grids 
were examined in a Leo 906 (Oberkochen, Germany) electron microscope at 80 $\mathrm{kV}$.

\section{RESULTS}

The Acot7 gene in mouse is located on chromosome 4 E2, and it was recently shown that the mouse and human Acot7 isoforms are encoded for by a single gene by alternative use of different first exons, resulting in proteins with different amino-terminal ends (14). The open reading frames are encoded for by nine exons, with exons 2-9 being identical for all isoenzymes. Four different alternative first exons were identified in the human gene, and 3 alternative first exons were identified in the mouse gene (24). In an attempt to elucidate the genomic organization of the gene encoding Acot7 in mouse, we initially searched the mouse EST database to identify any further variations in the 5'-region. Based on the database searches we identified 2 further possible first exons, as shown in Fig. 1A, that would result in proteins with the amino-terminal amino acid sequences as outlined in Fig. 1B. The remaining exons 2-9 were identical in all 5 gene products. The amino-terminal amino acid sequence of one of these variants conforms to a mitochondrial targeting sequence (ACOT7b), whereas the other 4 isoforms encode putative cytosolic enzymes, as described below. A recent change in nomenclature has been applied to acyl-CoA thioesterases and for the purpose of clarity, the new nomenclature is given in Table II, as there is a different nomenclature for gene and protein. Proteins in mouse are designated with a lower case suffix (e.g. ACOT7a) based on exon number, whereas the gene is designated as variant e.g. Acot1_variant 1 (Acot7_v1) etc. 


\section{Identification and mapping of alternative first exons in the Acot7a gene}

Previous work has shown that the major isoform of the Acot7 gene expressed in brain and testis is the cytosolic Acot7_v1 (previously known as CTE-II or BACHa) $(10,13)$. In order to characterize the mouse gene encoding the Acot7_v1, searches were carried out in mouse EST databases for different 5' ends of Acot7. The EST sequences corresponding to the different first exons were mapped and the genomic position was also mapped by blast alignments against the mouse genome sequence. This first exon is located most $5^{\prime}$ in the genomic sequence and is denoted Exon 1a (Fig. 1A). The mouse Acot7_v1cDNA sequence was assembled using overlapping EST sequences. Interestingly the ESTs could be divided into two groups, one group of ESTs that would encode a shorter protein of 338 amino acids with a calculated mass of $37.6 \mathrm{kDa}$. The deduced amino acid sequence of the shorter ACOT7a starts Met-Ser-Gly, and contains 15 amino acids encoded for by the first exon (as shown in Fig. 1A and B, with the start methionine indicated by an asterisk). However, the second group of ESTs contained longer 5'sequences, and the EST containing the longest 5'-sequence (Accession Number CA463703) encodes another 41 amino acids, resulting in a protein of 379 amino acids with a calculated molecular mass of $41.6 \mathrm{kDa}$, with two further in-frame methionines (Fig. 1A and B). Interestingly, we found four ESTs that encode the longer ACOT protein, named ACOT7g (start methionine indicated by \#) (Accession Numbers CA463703, CA4644199, CB273453 and BY090855), three of which were derived from testis and one from mixed tissues including testis, respectively. In an elegant study Takagi et al showed that exon 1a contains two tandemly located initiator elements between the second and third ATG codons that function as transcription start sites, which could explain the presence of the 
short and long Acot7_v1 (ACOT7a) and Acot_v7 (ACOT7g) mRNAs (22). Notably, all detected ESTs from brain encode the shorter Acot7a protein (methionine *), suggesting that the first exon is differently transcribed in different tissues. This was confirmed using Q-PCR, which shows that all mRNA expressed in testis encodes Acot7_v7 (ACOT7g) (see later). This expression pattern is also in agreement with the Western blot data, showing strong expression of two bands in testis (see Fig. 2B).

Of the aligned blast hits, a further 8 ESTs with extended 5' sequences of varying lengths were assembled into a unique contig. For two of these EST clones (AA466273 and AA103190, purchased from UK HGMP Resource Centre (Hinxton, Cambridge, UK)) we determined the complete sequence. Sequence analysis identified 58 amino acids in the $5^{\prime}$ end of these clones that were encoded for by an alternative first exon, denoted exon $1 \mathrm{~b}$ (Fig. 1A and B), with the remaining 323 amino acids being identical to the mouse Acot7a sequence (encoded for by exons 2-9). Examination of the $\mathrm{N}$-terminal amino acid sequence (PSORT II, http://psort.nibb.ac.jp) revealed that it possessed the characteristics of a mitochondrial targeting signal, and correspond to the previously characterized MTE-II or BACHb $(8,14)$. The mitochondrial localization was confirmed by green Fluorescent Protein (GFP) experiments (see below). In addition a further EST (Accession Number BY134190) was identified that extended further 5', and encodes 3 more amino acids (Met-Ser-Ala) in the Nterminal end, with the start methionine indicated underlined and in bold face (Fig 1B). The compiled cDNA sequence for Acot7_v2 (ACOT7b) contains 1,497 $\mathrm{bp}$, of which 1,152 bp encodes the open reading frame. The predicted cleavage 
site of the ACOT7b mitochondrial targeting peptide is indicated in Fig. 1B. This putative cleavage site (V-R-T $\square R-A)$ conforms to the 'R-2' class of cleavage sites $[(\mathrm{V} / \mathrm{A} / \mathrm{S})-\mathrm{R}-\mathrm{X} \square \mathrm{X}-(\mathrm{S} / \mathrm{A})]$ described by Schneider et al (23) and results in a mature ACOT7b protein that is 47 amino acids shorter, with a molecular weight of 37.6 $\mathrm{kDa}$, similar to the Acot7a isoform.

\section{Identification of three further putative $1^{\text {st }}$ exons}

The genome alignment of the assembled mouse Acot7 EST sequences identified three other possible $1^{\text {st }}$ exons. The first exon of one of these ESTs (BI409186, expressed in lung) maps 3' of Exon Ia, and was denoted Exon Id. The splice donor site of Exon Id (A $\underline{\mathrm{AT}}$ GAT) differs slightly to the general splice site consensus sequence, and encodes a methionine (underlined) in BI409186 in place of the common arginine (Fig. 1B). This methinone is the start methionine of BI409186. The splice donor sites of the other isoforms conform more strictly to the general consensus for splice donor sites (AAG, GAG, CCG), all of which encode an arginine (Fig. 1B). Another exception is Exon Ic, which contains an inframe stop codon in the area of the putative first alternative exon, and therefore the open reading frame starts with the first methionine in Exon II common to all isoenzymes. Three ESTs were identified, CA535335 and CK333208 isolated from mixed tissues, and AA275842 isolated from kidney, that are encoded by Exon Ic. Kuramochi et al identified a 5'-RACE cDNA in mouse (called MBACH-K2), resulting in a protein that is 29 amino acids longer in the $\mathrm{N}$-terminal end (16). We have now identified one EST (CX225643) that corresponds to a differently spliced version of Exon Ic, lacking the in-frame stop codon (see Fig. 1B). A fifth putative 
first exon (Exon Ie) was identified based on the EST BY346013, which encodes six amino acids (Fig. 1A and B).

The entire gene spans approximately $93.7 \mathrm{~kb}$, of which exons Ia to exon II spans about $28 \mathrm{~kb}$. The sizes of the various first exons are; Ia $>241 \mathrm{bp} ; \mathrm{Ib}>252 \mathrm{bp}$; Ic $>222$ bp; Id $>95 \mathrm{bp}$; and Ie $>129 \mathrm{bp}$. Thus, the sizes of the transcripts generated by alternative usage of the different first exons are very similar, with only about 125 bp difference between the smallest and largest transcripts. Expression of all five first exons was verified by Q-PCR as described below.

\section{Tissue expression of Acot7 mRNA transcripts}

Previous data has shown that in rat (24) and mouse (16), the expression of the Acot7_v1 transcript and protein is mainly confined to brain and testis. To further investigate the tissue expression of Acot isoenzymes, we examined the mRNA and protein levels in both male and female mouse tissues. Using a radiolabelled full-length cDNA probe for Acot7_v2 (which will recognize all Acot7 thioesterase isoforms), Northern blot analysis identified transcripts of slightly different sizes in all tissues. In male mice, Acot7 expression was highest in testis, followed by brain, but expression was also detected in lung and heart, with weak expression in the other examined tissues (liver, muscle, spleen kidney, brown (BAT) and white (WAT) adipose tissue (Fig. 2A). A smaller transcript was detected in brain, lung, muscle, WAT and testis, and a slightly larger transcript was detected in liver, kidney, heart and BAT. The larger transcript likely represents both Acot7_v2 (mitochondrial) and the longer Acot7_v7 mRNAs, and cannot be resolved by Northern blot analysis. 
Western blot analysis of male mouse tissue samples showed strongest expression in brain (a band that migrates as a $43 \mathrm{kDa}$ protein), followed by testis (Fig. 2B). There is evidently a poor correlation between mRNA and protein levels in testis and brain, with much higher protein levels in brain compared to mRNA, while testis contains a higher amount of mRNA than protein (similar to what has previously been reported in rat and mouse, see $(11,16))$, suggesting regulation also at the post-transcriptional level. In addition, strong expression was detected in lung, with weak expression in kidney, heart, spleen and WAT. Notably, the major band detected in liver migrates as a $50 \mathrm{kDa}$ band, similar to a second band detected in testis. The discrepancy between calculated molecular masses (37.6 and $41.6 \mathrm{kDa}$ ) and migration on SDS-PAGE (43 and $50 \mathrm{kDa}$ ) has been described previously (16), and is most likely due to the non-globular structure of the ACOT7 thioesterase proteins. Domain analysis suggests that the ACOT7a consists of two homologous domains connected by a hinge region (data not shown).

As the individual isoforms appeared to be differently expressed in a variety to tissues, which could not be resolved by Northern blot analysis, we therefore carried out real-time PCR using primers specific for each of the 5 isoforms identified. Q-PCR was carried out on pooled total RNA from liver, brain, spleen, lung, kidney, testis and heart. Exon Ia of Acot7 contains two alternative start methionines, resulting in proteins ACOT7a and ACOT7g, therefore primers were designed to amplify both the Acot7_v7 (methionine\# - ACOT7g) and Acot7_v1 (methionine* - ACOT7a) versions of this mRNA (methionines indicated in Fig. 
1B). Q-PCR was used to amplify both Acot7_v1 (shorter mRNA) and Acot7_v7 (longer mRNA) and calculation of the mRNA levels of the individual isoforms of Acot7_v1 and Acot7_v7 was carried out as follows:- Primers for Acot7_v1 will recognize both the Acot7_v1 and the Acot7_v7 isoforms, whereas primers for Acot7_v7 are specific only for Acot7_v7, therefore if the level of expression of both isoforms was the same in a tissue (as in testis, liver and heart), then all the mRNA related to the Acot7_v7 (the longer mRNA). If a tissue contained different expression levels of both these isoforms, then the net expression of the Acot7_v1 was calculated by subtracting the expression level of the Acot7_v7 from the Acot7_v1. The Acot7_v7 is very highly expressed in testis, being 90 -fold higher than expression in brain and heart. The Acot7_v1 is mainly expressed in brain, lung, and spleen, however, in testis all ACOT7a mRNA is accounted for by Acot7_v7 (Fig. 3A).

Alternative splicing results in five Acot7 isoforms, three of which have not previously been characterized, and as was evident from Northern blot analysis, it appeared that these transcripts were differently expressed in different tissues. QPCR was to used to examine if the alternative use of the first exons results in transcripts that are expressed in different tissues. The mitochondrial Acot7_v2 (previously MTE-II or BACHb) has been described in human, but was expressed at only very low levels in human brain compared to Acot7_v1, the cytosolic enzyme (14). Q-PCR from mouse tissues showed that Acot7_v2 is mainly expressed in heart and lung, with lower levels present in brain and spleen (Fig 3B). Interestingly, the three newly identified isoforms, Acot7_v3, Acot7_v4 and 
Acot7_v5 were all expressed, albeit at a low level compared to Acot7_v1 or Acot7_v2. Acot7_v3 was highest in spleen, lung, kidney and testis whereas Acot7_v4 was highest in brain, with detectable levels also in lung (Fig. 3C and 3D). Acot7_v5 was highest in spleen, heart and lung (Fig. 3E). It should be emphasized that based on the Q-PCR data, it can be concluded that the Acot7_v1 and Acot7_v7 (cytosolic) are the most highly expressed isoforms, followed by the Acot7_v2 isoform (mitochondrial), and these mRNAs are expressed to a much higher level than the other three isoforms Acot7_v3, _v4 and _v5.

\section{Tissue expression of Acot7 in female mice}

In female mice, mRNA expression of Acot7 isoforms was highest in brain, lung, kidney, heart and ovary (Fig. 4A). In heart and BAT, expression of a larger transcript dominated. Western blot analysis also confirmed these findings, with highest expression in brain, followed by lung, kidney, heart, spleen, ovary and BAT (Fig. 4B). Q-PCR was not carried out on mRNA from female mice.

\section{Expression of ACOT7a and ACOT7b in mitochondrial and cytosolic fractions}

Due to the very high sequence similarity between Acot7 gene products, the antiAcot7 antibody cannot distinguish between the different isoforms. Therefore to further distinguish between mitochondrial and cytosolic expression of ACOT7 isoforms in mice, we fractionated liver, brain, lung, spleen and heart homogenates into mitochondria and cytosol, and analyzed these fractions by Western blotting (Fig. 5). In mitochondria from liver, a single band of about 43 
$\mathrm{kDa}$ was detected, and a single band of about $50 \mathrm{kDa}$ was detected in cytosol. This confirms the expression of the longer ACOT7g protein in liver cytosol, whereas liver mitochondria contain ACOT7b protein. We also analyzed mitochondrial and cytosolic fractions prepared from other tissues, which showed that it is mainly the cytosolic enzyme(s) that is/are expressed in lung, spleen and heart. In brain there was a substantial expression of ACOT7 cytosolic proteins and the mitochondrial ACOT7b protein. The ACOT7g protein of $50 \mathrm{kDa}$ was only detected in liver cytosol, with the cytosolic fractions from other tissues containing only the smaller $43 \mathrm{kDa}$ ACOT7 cytosolic proteins (Acot7a, 7c, 7d and 7e). Again, there was a weak correlation between protein levels and mRNA in various tissues. ACOT7b, the mitochondrial isoform, shows highest mRNA levels in heart, whereas low protein levels were detected in heart mitochondria.

\section{Localization of ACOT7a and ACOT7b in cytosol and mitochondria}

To examine the intracellular localization of the main ACOT7 isoforms expressed, ACOT7a and ACOT7b, we cloned these proteins in-frame with green fluorescent protein (GFP), which leaves the amino-terminal end accessible. We transfected these constructs into human skin fibroblasts. Using immunofluorescence microscopy for detection of a Tritc-labeled secondary antibody to GFP, transfection of the ACOT7a/CT-GFP plasmid showed a strong, diffuse staining, resembling a cytosolic localization (Fig. 6A). Direct analysis of the GFP signal showed that ACOT7b had a distinctive pattern of expression, indicative of a mitochondrial localization (Fig. 6B). This was confirmed using a Mitotracker Orange $^{\mathrm{TM}}$, which confirmed the structures as mitochondria (Fig. 6C). Sequence analysis of the amino-terminal ends of the other ACOT7 isoenzymes identified 
did not reveal similarity to mitochondrial targeting signals, and are therefore likely to be localized in cytosol.

\section{ACOT7b is highly expressed in late spermatids in testis}

As the Acot7 thioesterases are highly expressed in testis at both mRNA and protein level, we further examined the localization of the ACOT7 protein in this organ. Immunoelectron microscopy showed specific labeling for ACOT7b preferentially in, and in the vicinity of, mitochondria in the late spermatids (Fig. 7A and B). Most of the labeling was detected in the mitochondria around the sperm tail, indicating that ACOT7b protein is highly expressed in testis. Weak labeling was detected in the surrounding cytoplasm, as well as in the cytoplasm of surrounding cells. Labeling with normal serum was homogenously distributed and at the background level indicating an unspecific binding.

\section{Discussion}

The Acot7 gene has previously been studied in human and mouse, and shown to be highly expressed in brain and testis. However, only little is known about the expression in other tissues. Our recent finding that screening of patients with undefined fatty acid oxidation deficiencies was associated with markedly decreased ACOT7 activity and protein levels in cytosol and mitochondria (25), suggested that these enzymes could have more diverse functions than previously envisaged. Molecular characterization showed that the ACOT deficiency was in fact due to decreased expression of ACOT7 in cytosol and mitochondria. Interestingly, ACOT7 activity was responsible for about $80-90 \%$ of the total 
activity in cytosol and mitochondria in human skin fibroblasts. These data suggest that ACOT7 expression is indeed considerable in other tissues beside brain and testis. The aim of this study was to investigate the complex transcriptional activity of the $A \cot 7$ gene, and to investigate the expression of Acot7 isoforms in a broader spectrum of tissues in more detail. Here we show that the Acot7 gene is transcribed into at least five different mRNAs in mouse, due to the presence of five different first exons termed Exons Ia-e. Exon Ia encodes the major brain/testis cytosolic isoenzyme, described previously from rat and human. Using GFP fusion experiments we show that indeed this isoenzyme is localized in cytosol. Interestingly exon 1a contains three in-frame ATG codons, and it was shown by Takagi et al that there are two Inr elements (Inr 1 and Inr 2) located in tandem between the second and third ATG that can mediate transcription (22). Translation from ATG 3 would result in a protein of 338 amino acids, while translation from the first ATG results in a protein of 379 amino acids. Interestingly, exon Ia (encoding the ACOT7g 379 amino acid protein) is highly expressed in testis, and is the main isoform expressed in liver, kidney and heart. None of the ESTs corresponding to the Acot7_v7 was expressed in brain tissue, in agreement with the real time data, showing that it is the Acot7_v7 that is expressed in testis. Analysis of the amino-terminal 41 amino acid extension did not indicate that it would constitute a mitochondrial targeting peptide, and the cytosolic localization of this longer ACOT7g was further strengthened by the apparent cytosolic localization of this $50-\mathrm{kDA}$ protein from fractionation of mouse liver homogenates (Fig. 5) and from GFP-localization experiments (22). Exon Id does not contain any coding sequence and is translated from exon 2, which results in a protein of 323 amino acids. Exon Ie encodes six 
amino acids, giving a protein of 329 amino acids in total. Exon $\mathrm{Ib}$ encodes the mitochondrial isoenzyme, which was confirmed by GFP-localization experiments. The protein was detected immunologically in liver, lung and testis but mRNA was mainly detected in heart. Finally, splicing of exon Ic results in an in-frame stop codon, which produces a protein of 321 amino acids. We found three ESTs that were all spliced in this manner. However, the MBACK-K2 described by Kuramochi et al (16) is also encoded by this exon, but was spliced $123 \mathrm{bp}$ further $5^{\prime}$, and therefore lacks the in-frame stop codon. Database searches identified one EST from rat that corresponded to the mouse exon Ic, which was spliced in a similar manner to the mouse gene exon Ic. In contrast, the human gene expresses an exon that is similar to the $\mathrm{MBACH}-\mathrm{K} 2$ variant, and which in human encodes a second mitochondrial ACOT7, named human ACOT7c (14).

Recent studies have demonstrated a very high degree of sequence conservation of the rat, mouse and human genes, which show $>95 \%$ identity at amino acid level. However, these studies have also identified several isoenzymes of acylCoA thioesterases, some of which are different in human and mouse. Therefore, the reason for the multitude of isoenzymes formed by the alternative use of different first exons is not yet clear. One obvious function is the expression of a mitochondrial isoenzyme that probably plays a role in mitochondrial fatty acid metabolism. The mitochondrial isoenzyme (ACOT7b) was identified and characterized in rat liver as being strongly upregulated by treatment of rats with peroxisome proliferators (8), which act as ligands for the peroxisome proliferator-activated receptor alpha (PPAR $)$ ), a nuclear receptor involved in controlling lipid metabolism (26-29). The strong regulation of expression of 
$\mathrm{ACOT7b}$ in rat liver by peroxisome proliferators suggests an involvement of ACOT7b in regulation of fatty acid metabolism. Both the cytosolic and mitochondrial enzymes are upregulated in rat liver following this treatment $(10,11)$. However, it was previously shown that the cytosolic ACOT7a enzyme is not upregulated in liver by treatment of mice with peroxisome proliferators, indicating a species-specific responsiveness (30). Using both semi-quantitative PCR and size-exclusion chromatography to analyze regulation of Acot7_v1 and Acot7_v2 in livers of mice treated with the peroxisome proliferators WY-14,643 or clofibrate, our data show only a minor induction of the mitochondrial ACOT7b in mouse liver (both activity and mRNA) following treatment with WY-14,643 or clofibrate, whereas no upregulation was detected in the cytosolic fraction (data not shown). Further support for a role of ACOT7b in regulation of fatty acid metabolism stems from our finding that ACOT7b is apparently highly expressed in mitochondria in late spermatids, where these mitochondria are associated to the sperm tail. These mitochondria are small, rounded and dense with condensed matrix and expanded cristae, suggestive of high metabolic activity. Cytosolic ACOT7 is also expressed in spermatids, but not in spermatogonia (22) suggesting that the expression of the Acot7 gene is restricted to spermatids. In rat, ACOT7b and/or ACOT7a expression is upregulated also in testis both at mRNA and protein level after treatment with peroxisome proliferators $(10,12)$.

Another further reason for the existence of numerous alternative first exons may be to mediate tissue specific expression of Acot7. This notion is supported by our data from the Q-PCR and Western blot analyses showing a pronounced tissue selective expression of different transcripts and proteins. Although previous 
studies have suggested that ACOT7a is mainly localized in brain and testis in rat $(10,12,31)$, our study now shows that these Acot7 isoenzymes have a much broader tissue expression in mouse than previously thought. It is evident that different Acot7 isoenzymes are expressed in a tissue selective manner, for example the $41.6 \mathrm{kDa}$ protein is expressed in liver, testis, and although very weakly, also in heart and brown adipose tissue. Although expression is much higher in brain and testis than in other tissues tissues, it should be kept in mind that the specific activity of the ACOT7 proteins are generally much higher than the specific activities of most other ACOTs, and would therefore be likely to significantly contribute to the cellular activity in other tissues. This is evident from data obtained with human skin fibroblasts which showed that about $80 \%$ of the activity in mitochondria and cytosol could be immunoprecipitated using an anti-ACOT7 antibody (25).

Our data, and previous studies, show that there is little correlation between the protein and mRNA expression of Acot7 in tissues, in particular when comparing the mRNA and protein expression in brain and testis. It has been shown that Acot7 isoenzymes account for approximately $80-90 \%$ of the acyl-CoA thioesterase activity in brain $(13,16)$. However, mRNA is mainly detected in testis, with lower levels in brain and even lower levels in the other tissues, although protein is highest in brain, followed by testis, lung and lower in the other tissues. It appears that the poorest correlation between mRNA and protein is seen in testis. As discussed above and by Takagi et al (22), Acot7 is specifically expressed in spermatids, in which certain mRNAs have been reported to assemble into messenger ribonucleoprotein particles, which temporarily repress translation. 
Such a post-transcriptional regulation of translation may play important functions under conditions when new mRNA is not being synthesized.

Besides PPAR $\square$ regulation in rat, only little is known about other factors that can regulate transcription of the $A \cot 7$ gene. It is possible that the different first exons may allow selective regulation of expression by various hormones or other factors. ACOT7 expression was found to be upregulated in porcine corpus luteum during pregnancy (32) indicating hormonal regulation, and which may also be in line with the pronounced expression seen in mouse ovaries. Recently, the human $A \cot 7$ a promotor was found to be regulated by SREBP-2 via a sterol regulatory element (SRE) (33), although the role of this regulation is not yet clear.

The functions of the various ACOT7 isoenzymes are not yet fully clarified. It has been speculated that these enzymes may play a role in lipid synthesis, however, over-expression of the ACOT7a in Chinese hamster ovary $(\mathrm{CHO})$ and $\mathrm{C} 3 \mathrm{H}$ 10T1/2 fibroblastic cells did not result in any change in phospholipid synthesis or incorporation of palmitate into various lipid fractions in the cells $(10,34)$. Although some cell lines, for example CHO cells (10), express high levels of ACOT7a, over-expression of ACOT7a in C3H 10T1/2 fibroblastic cells reduced cell growth. Therefore, it is possible that ACOT7a does not have a general function in regulation of acyl-CoA levels in cytosol, but rather plays a role in cellular signaling. Acot7a shows high activity towards arachidonoyl-CoA (35), and may therefore play a role in maintaining free arachidonic acid for signaling via arachidonic acid, or for prostaglandin synthesis. Another interesting aspect is that both brain and testis have a blood-tissue barrier. This barrier restricts 
lipoprotein-mediated uptake of fatty acids from the circulation and therefore brain and testis rely on endogenous fatty acid synthesis, especially 20 and 22 carbon polyunsaturated fatty acids (PUFAs). It may be therefore that Acot7a is involved in synthesis of complex lipids in these tissues. So far no patients have been identified with mutations linked to any particular disorder, but a derangement of ACOT7 protein has been detected in the hippocampus of patients with mesial temporal lobe epilepsy (36), and decreased levels of ACOT7 protein was detected in fibroblats from patients with undefined fatty acid oxidation disorders (25).

In conclusion, we have now identified five alternatively spliced Acot7 thioesterases, which are products of a single gene in mouse. Although these enzymes are likely to have a similar acyl-CoA chain length specificity, similar to the human gene family (14), it is apparent that the different first exons determine selective tissue expression and regulation of expression.

\section{Acknowledgements:}

This study is supported by the Swedish Research Council, AFA sjukförsäkrings jubileumsstiftelse, Åke Wibergs stiftelse, Hjärt-Lungfonden, Svenska Sällskapet för Medicinsk Forskning, Lars Hiertas Minne, Fredrik och Ingrid Thurings Stiftelse, Ruth och Richard Juhlins Stiftelse, Stifelsen Professor Nanna Svartz fond and National Network for Cardiovascular Research (Sweden). 
Abbreviations: Acot, acyl-CoA thioesterase; Q-PCR, quantitative polymerase chain reaction, DEHP, di(2-ethylhexyl)phthalate; GFP, green fluorescent protein; EST, expressed sequence tag; bp, base pair. 


\section{FIGURE LEGENDS}

Fig. 1. Organization of the $5^{\prime}$-end of the Acot7 gene. (A) The location of the five alternative first exons (Ia- Ie) is depicted by filled boxes, and Exon II is depicted by an open box. Exon 1a is magnified to shown the location of two tandemly located initiator motif element motifs (Inr) that are involved in alternative transcription of Exon Ia. The two alternative start ATG codons are indicated by \# (encoding a 379 amino acid protein - ACOT7g) and * (encoding a 338 amino acid protein - ACOT7a). The intron sizes were calculated from the genomic contigs AL772240, AL 671869 and AL 611985. (B) Deduced amino acid sequences for the $\mathrm{N}$-terminal ends of the various isoenzymes produced by alternative use of different first exons. The designation of the different first exons (Ia-e) are shown on the far right side. The location of Exon II is indicated by a solid line [. Predicted start methionines are underlined and in bold face. The start methionine for the shorter version of ACOT7a is indicated by an asterisk *, whereas the start methionine for the longer version denoted as ACOT7g is indicated by \#. An arrow indicates the predicted cleavage site for the mitochondrial targeting peptide in Acot7b.

Fig. 2. Tissue expression of $A \cot 7$ in male SV/129 mice. (A) Total RNA was isolated from various tissues from male SV/129 mice. Northern blot analysis was

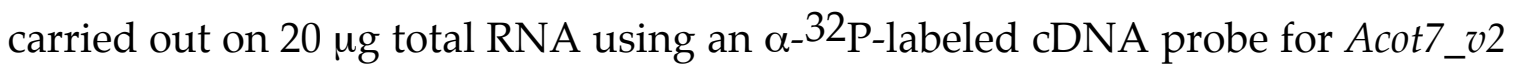
as described in Experimental Procedures. BAT, brown adipose tissue; WAT, white adipose tissue. Sizes of mRNAs are shown. (B) Western blot analysis was 
carried out on $100 \square g$ of homogenate protein from various tissues from male SV/129 mice, using an anti-ACOT7 antibody as described in Experimental procedures. BAT, brown adipose tissue; WAT, white adipose tissue. The protein size is shown in $\mathrm{kDa}$.

Fig. 3. Tissue expression of Acot7 isoforms in male SV/129 mice using Q-PCR. Tissue expression of $A \cot 7$ isoforms was investigated in mouse tissues using single-plex Q-polymerase chain reaction (PCR). Total RNA was prepared from 3 animals, which was pooled for each tissue and cDNA was prepared from pooled RNA samples. Q-PCR was carried out in triplicate for each tissue, using mouse Hprt mRNA as a control. The value for pooled liver for each isoform was set to 1 and the relative expression in tissues calculated. Primers for Acot7_v1 (7a) also recognize the Acot7_v7 (7g) as these are encoded by the same exon, however primers for Acot7_v7 (7g) are specific for this isoform. Therefore the relative mRNA levels of Acot7_v1 (ACOT7a) and Acot7_v7 (ACOT7g) were calculated by subtracting the values for Acot7_v7 from the values for Acot7_v1 where appropriate (as outlined in Results section). The amount of mRNA relative to liver was calculated using the $2^{-\square \square C T}$ method. (A) Acot7_v1 (ACOT7a) and Acot7_v7 (ACOT7g) (B) Acot7_v2 (ACOT7b) (C) Acot7_v3 (ACOT7c) (D) Acot7_v4 (ACOT7d) (E) Acot7_v5 (ACOT7e).

Fig. 4. Tissue expression of ACOT7 acyl-CoA thioesterases in female SV/129 mice. (A) Total RNA was isolated from various tissues from female SV/129 mice. Northern blot analysis was carried out on $20 \square \mathrm{g}$ total RNA using an $\square^{-32} \mathrm{P}-$ 
labeled cDNA probe for Acot7_v2 as described in Experimental Procedures. BAT, brown adipose tissue; WAT, white adipose tissue. Sizes of mRNAs are shown. (B) Western blot analysis was carried out on $100 \square g$ of homogenate protein from various tissues from female SV/129 mice, using an anti-ACOT7 antibody as described in Experimental procedures. BAT, brown adipose tissue; WAT, white adipose tissue. The protein size is shown in $\mathrm{kDa}$.

Fig. 5. Western blot analysis of cytosolic and mitochondrial fractions from various tissues. Western blot analysis was carried out on $100 \square \mathrm{g}$ of cytosolic and mitochondrial fractions prepared from female SV / 129 mice using an anti-ACOT7 antibody as described in Experimental procedures. The protein size is shown in kDa.

Fig. 6. Cellular localization of ACOT7 thioesterases. (A) Human skin fibroblasts transfected with ACOT7a/CT-GFP and processed for immunofluorescence microscopy by fixation and permeabilization with $0.5 \%$ Triton X-100. The distribution of Acot7a was examined in fibroblasts using a Tritc-labeled anti-GFP antibody. (B) ACOT7b / CT-GFP was examined directly by immunofluorescence microscopy after fixation and permeabilization with $0.5 \%$ Triton X-100 (C) Mitotracker Orange ${ }^{\mathrm{TM}}$ CMTMRos.

Fig. 7. Electron micrograph of mouse testis. (A) Early spermatids (N) and late spermatids (arrows) containing high amount of mitochondria (B) Higher magnification showing the distribution of labeling for ACOT7b (arrowheads) in 
mitochondria (M) and axoneme (A) of a late spermatid. Notably, immunolabeling was only found in spermatids. Bars; $A=10 \mu \mathrm{m}, \mathrm{B}=0.5 \mu \mathrm{m}$. 


\section{REFERENCES}

1. Waku K. (1992) Origins and fates of fatty acyl-CoA esters Biochim. Biophys. Acta. 1124: 101-111

2. Færgeman N. J. and Knudsen J. (1997) Role of long-chain acyl-CoA esters in the regulation of metabolism and in cell signalling. Biochem. J. 323: 1-12

3. Hunt M. C. and Alexson S. E. H. (2001) The role acyl-CoA thioesterases play in mediating intracellular lipid metabolism. Prog. Lipid Res. 41: 99-130

4. Yamada J. (2005) Long-chain acyl-CoA hydrolase in the brain. Amino Acids. 28: 273-278

5. Miyazawa S., Furuta S. and Hashimoto T. (1981) Induction of a novel long-chain acyl-CoA hydrolase in rat liver by administration of peroxisome proliferators Eur. J. Biochem. 117: 425-430

6. Kawashima Y., Katoh H. and Kozuka H. (1982) Sex-related difference in the effect of clofibric acid on induction of two novel long-chain acyl-CoA hydrolases in rat liver. Biochim. Biophys. Acta. 712: 48-56

7. Katoh H., Nakajima S., Kawashima Y., Kozuka H. and Uchiyama M. (1984) Induction of rat hepatic long-chain acyl-CoA hydrolases by various peroxisome proliferators Biochem. Pharmacol. 33: 1081-1085

8. Svensson L. T., Alexson S. E. H. and Hiltunen J. K. (1995) Very long chain and long chain acyl-CoA thioesterases in rat liver mitochondria. Identification, purification, characterization, and induction by peroxisome proliferators J. Biol. Chem. 270: $12177-12183$

9. Hunt M. C., Yamada J., Maltais L. J., Wright M. W., Podesta E. J. and Alexson S. E. H. (2005) A revised nomenclature for mammalian acyl-CoA thiosterases/hydrolases. J. Lipid Res. 46: 2029-2032

10. Engberg S. T., Aoyama T., Alexson S. E. H., Hashimoto T. and Svensson L. T. (1997) Peroxisome proliferator-induced acyl-CoA thioesterase from rat liver cytosol: molecular cloning and functional expression in Chinese hamster ovary cells Biochem. J. 323: 525-531

11. Yamada J., Furihata T., Iida N., Watanabe T., Hosokawa M., Satoh T. et al. (1997) Molecular cloning and expression of cDNAs encoding rat brain and liver cytosolic long-chain acyl-CoA hydrolases Biochem. Biophys. Res. Commun. 232: 198-203

12. Broustas C. G., Larkins L. K., Uhler M. D. and Hajra A. K. (1996) Molecular cloning and expression of cDNA encoding rat brain cytosolic acyl-coenzyme A thioester hydrolase J. Biol. Chem. 271: 10470-10476

13. Yamada J., Kurata A., Hirata M., Taniguchi T., Takama H., Furihata T. et al. (1999) Purification, molecular cloning, and genomic organization of human brain long-chain acyl-CoA hydrolase. J. Biochem. 126: 1013-1019

14. Yamada J., Kuramochi Y., Takagi M., Watanabe T. and Suga T. (2002) Human brain acyl-CoA hydrolase isoforms encoded by a single gene. Biochem. Biophys. Res. Comm. 299: 49-56 
15. Yamada J., Kuramochi Y., Takagi M. and Suga T. (2004) Expression of acyl-CoA hydrolase in the developing mouse brain. Neurosci. Lett. 355: 89-92

16. Kuramochi Y., Takagi-Sakuma M., Kitahara M., Emori R., Asaba Y., Sakaguchi R. et al. (2002) Characterization of mouse homolog of brain acyl-CoA hydrolase: molecular cloning and neuronal localization. Mol. Brain Res. 98: 81-92

17. Altschul S. F., Gish W., Miller W., Myers E. W. and Lipman D. J. (1990) Basic local alignment search tool J. Mol. Biol. 215: 403-410

18. Hunt M. C., Lindquist P. J. G., Peters J. M., Gonzalez F. J., Diczfalusy U. and Alexson S. E. H. (2000) Involvement of the peroxisome proliferator-activated receptor alpha (PPAR $\square$ ) in regulation of long chain acyl-CoA thioesterases. J. Lipid Res. 41: 814-823

19. Hunt M. C., Solaas K., Kase B. F. and Alexson S. E. H. (2002) Characterization of an acyl-CoA thioesterase that functions as a major regulator of peroxisomal lipid metabolism. J. Biol. Chem. 277: 1128-1138

20. Tokuyasu K. T. (1973) A technique for ultracryotomy of cell suspensions and tissues. J. Cell Biol. 57: 551-565

21. Dinser R., Zaucke F., Kreppel F., Hultenby K., Kochanek S., Paulsson M. et al. (2002) Pesudoachondroplasia is caused through both intra- and extracellular pathogenic pathways. J. Clin. Invest. 110: 505-513

22. Takagi M., Kawabe K., Suga T. and Yamada J. (2004) A 50-kDa isoform of mouse brain acyl-CoA hydrolase:expression and molecular properties. Arch. Biochem. Biophys. 429: 100-105

23. Schneider G., Sjöling S., Wallin E., Wrede P., Glaser E. and von Heijne G. (1998) Feature-extraction from endopeptidase cleavage sites in mitochondrial targeting peptides. Proteins. 30: 49-60

24. Yamada J., Furihata T., Tamura H., Watanabe T. and Suga T. (1996) Long-chain acyl-CoA hydrolase from rat brain cytosol: purification, characterization, and immunohistological localization Arch. Biochem. Biophys. 326: 106-114

25. Hunt M. C., Ruiter J., Mooyer P., van Roermund C. W. T., Ofman R., Ijlst L. et al. (2005) Identification of fatty acid oxidation disorder patients with lowered acyl-CoA thioesterase activity in human skin fibroblasts. Eur. J. Clin. Invest. 35: 38-46

26. Lee S. S., Pineau T., Drago J., Lee E. J., Owens J. W., Kroetz D. L. et al. (1995) Targeted disruption of the alpha isoform of the peroxisome proliferator-activated receptor gene in mice results in abolishment of the pleiotropic effects of peroxisome proliferators. Mol. Cell. Biol. 15: 3012-3022

27. Leone T. C., Weinheimer C. J. and Kelly D. P. (1999) A critical role for the peroxisome proliferator-activated receptor $\square$ (PPAR $\square$ ) in the cellular fasting response: The PPAR $\square$-null mouse as a model of fatty acid oxidation disorders. Proc. Natl. Acad. Sci. U.S.A. 96: 7473-7478

28. Aoyama T., Peters J. M., Iritani N., Nakajima T., Furihata K., Hashimoto T. et al. (1998) Altered constitutive expression of fatty acid-metabolizing enzymes in mice lacking the peroxisome proliferator-activated receptor alpha (PPAR alpha) J. Biol. Chem. 273: 5678-5684 
29. Kersten S., Seydoux J., Peters J. M., Gonzalez F. J., Desvergne B. and Wahli W. (1999) Peroxisome proliferator-activated receptor $\square$ mediates the adaptive response to fasting. J. Clin. Invest. 103: 1489-1498

30. Kawashima Y., Katoh H., Nakajima S. and Kozuka H. (1983) Induction of hepatic long-chain acyl-CoA hydrolase by clofibric acid administration Biochim. Biophys. Acta. 752: 182-185

31. Yamada J., Matsumoto I., Furihata T., Sakuma M. and Suga T. (1994) Purification and properties of long-chain acyl-CoA hydrolases from the liver cytosol of rats treated with peroxisome proliferator. Arch. Biochem. Biophys. 308: $118-125$

32. Boström M., Alexson S. E. H., Lundgren B., Dean Nelson B. and DePierre J. W. (2004) The expression of cytosolic and mitochondrial type II acyl-CoA thioesterases is upregulated in the porcine corpus luteum during pregnancy. Prostaglandins Leukot. Essent. Fatty Acids. 71: 319-327

33. Takagi M., Suto F., Suga T. and Yamada J. (2005) Sterol regulatory elementbinding protein-2 modulates human brain acyl-CoA hydrolase gene transcription. Mol. Cell. Biochem. 275: 199-206

34. Takagi M., Yamakawa H., Watanabe T., Suga T. and Yamada J. (2003) Inducible expression of long-chain acyl-CoA hydrolase gene in cell cultures. Mol. Cell. Biochem. 252: 379-385

35. Broustas C. G. and Hajra A. K. (1995) Purification, properties, and specificity of rat brain cytosolic fatty acyl coenzyme A hydrolase J. Neurochem. 64: 2345-2353

36. Yang J. W., Czech T., Yamada J., Csaszar E., Baumgartner C., Slavc I. et al. (2004) Aberrant cytosolic acyl-CoA thioester hydrolase in hippocampus of patients with mesial temporal lobe epilepsy. Amino Acids. 27: 269-275 
Table I: Sequence of Sybrgreen primers used for Q-PCR. The 3' primer used was identical for each $A \cot 7$ gene product, as this primer is located in the second exon, which is common to all genes.

\begin{tabular}{|l|l|l|}
\hline $\begin{array}{l}\text { Gene } \\
\text { product }\end{array}$ & $\mathbf{5}^{\prime}$ primer & $\mathbf{3}^{\prime}$ primer \\
\hline Acot7_v1 & TCCGGCCCCACCACAGACACG & CCACATTGGCATCATCTGGAC \\
\hline Acot7_v2 & AGGGACACGGGACTTTCCCTG & CCACATTGGCATCATCTGGAC \\
\hline Acot7_v3 & CGGGACCTCTGCCTCACTT & CCACATTGGCATCATCTGGAC \\
\hline Acot7_v4 & CATGAGGGCTGTCAGAACCA & CCACATTGGCATCATCTGGAC \\
\hline Acot7_v5 & CTGGGATGCTTTGGTGTCCT & CCACATTGGCATCATCTGGAC \\
\hline Acot7_v7 & CTCCCAGGCTCATTCATTCG & CCACATTGGCATCATCTGGAC \\
\hline Hprt & GGTGAAAAGGACCTCTCGAAGTG & ATAGTCAAGGGCATATCCAACAACA \\
\hline
\end{tabular}


Table II: Protein and gene nomenclature for Acot7 isoenzymes. The exon encoding the various gene products are given. * and \# refer to methionines in Fig. $1 B$.

\begin{tabular}{|l|l|l|}
\hline Protein Nomenclature & Gene Nomenclature & Exon Number \\
\hline ACOT7a *meth & Acot7_vl & Ia \\
\hline ACOT7g \#meth & Acot7_v7 & Ia \\
\hline ACOT7b & Acot7_v2 & Ib \\
\hline ACOT7c & Acot7_v3 & Ic \\
\hline ACOT7e & Acot7_v5 & Id \\
\hline & Acot7_v4 & \\
\hline & & \\
\hline & & \\
\hline
\end{tabular}


Hunt et al.

Fig 1

\section{A}

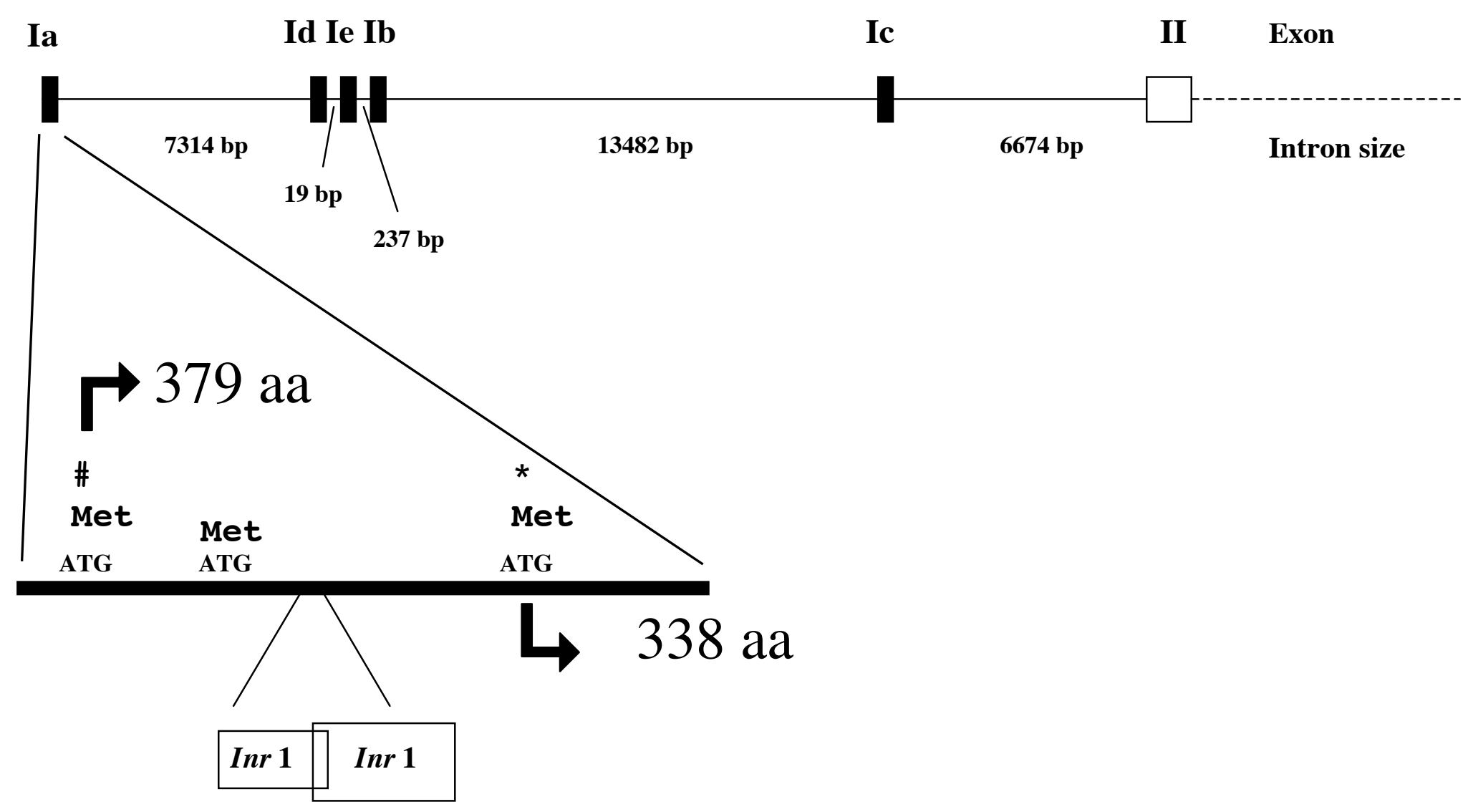




\section{Hunt et al.}

Fig. 1

B

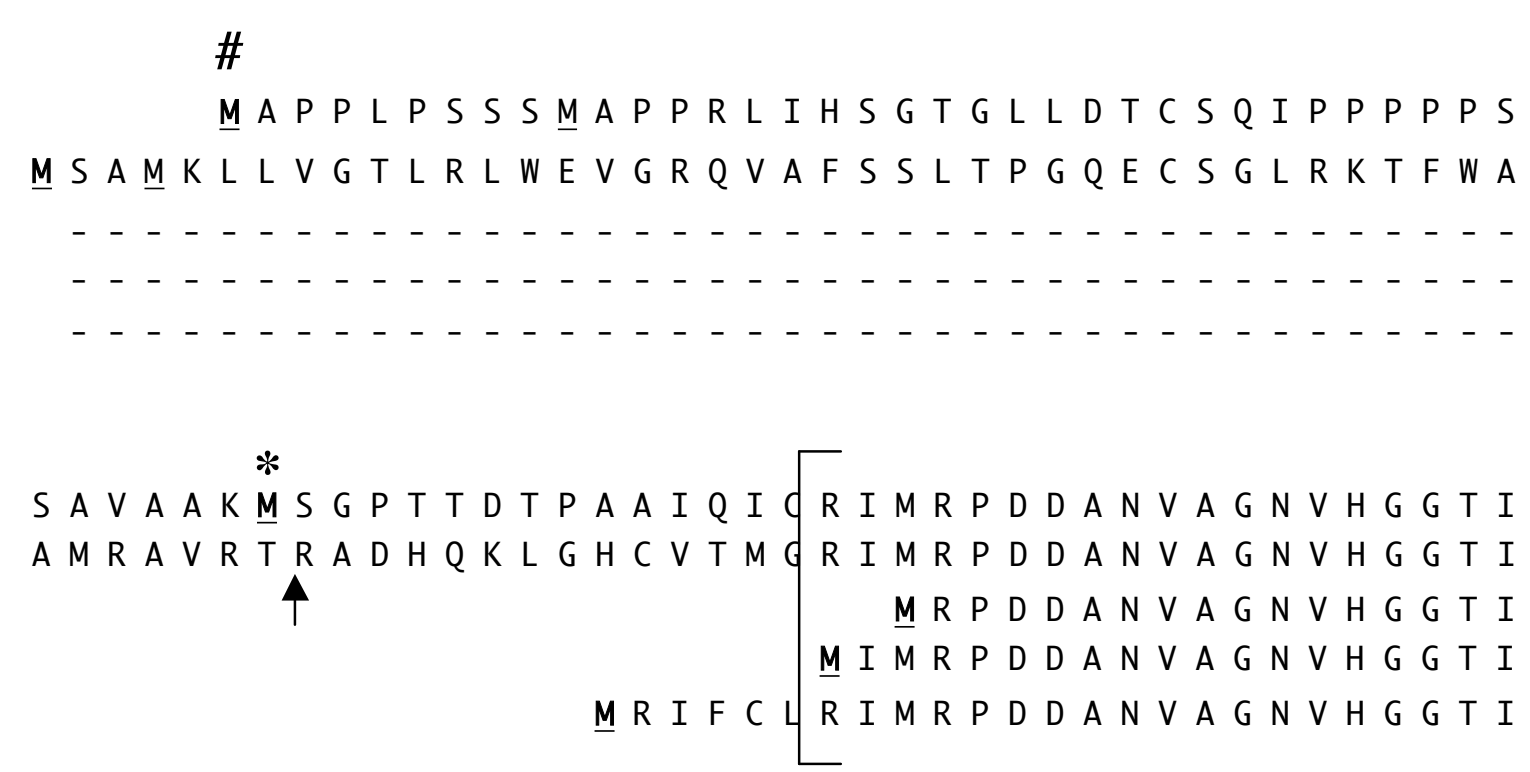

$\#$

M A P P L P S S S M A P PRL I HSG TGLLDTCSQ I P P P P P S M S A M K L LVGTLRLWEVGRQVAFS SLTPGQECSGLRKTFWA $M R I F C L R$

\section{Exon}

Acot7a (*) and 7g (\#) (Ia) Acot7b (Ib)

Acot7c (Ic)

Acot7d (Id)

Acot7e (Ie)

Acot7a (*) and 7g (\#) (Ia)

Acot7b (Ib)

Acot7c (Ic)

Acot7d (Id)

Acot7e (Ie)

\section{Exon II}


Hunt et al.

Fig. 2

A

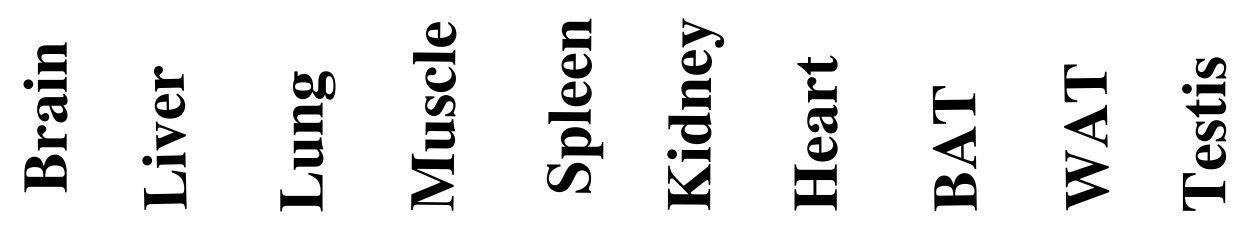

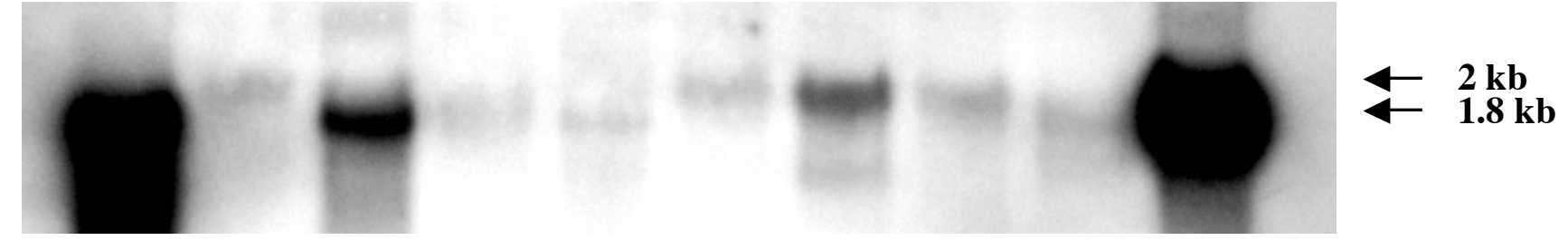

B

$$
\begin{aligned}
& \text { 毼 } \\
& \leftarrow 50 \mathrm{kDa} \\
& \leftarrow 43 \mathrm{kDa}
\end{aligned}
$$


Hunt et al.

Acot7_v1 (7a) and Acot7_v7 (7g)

Fig 3

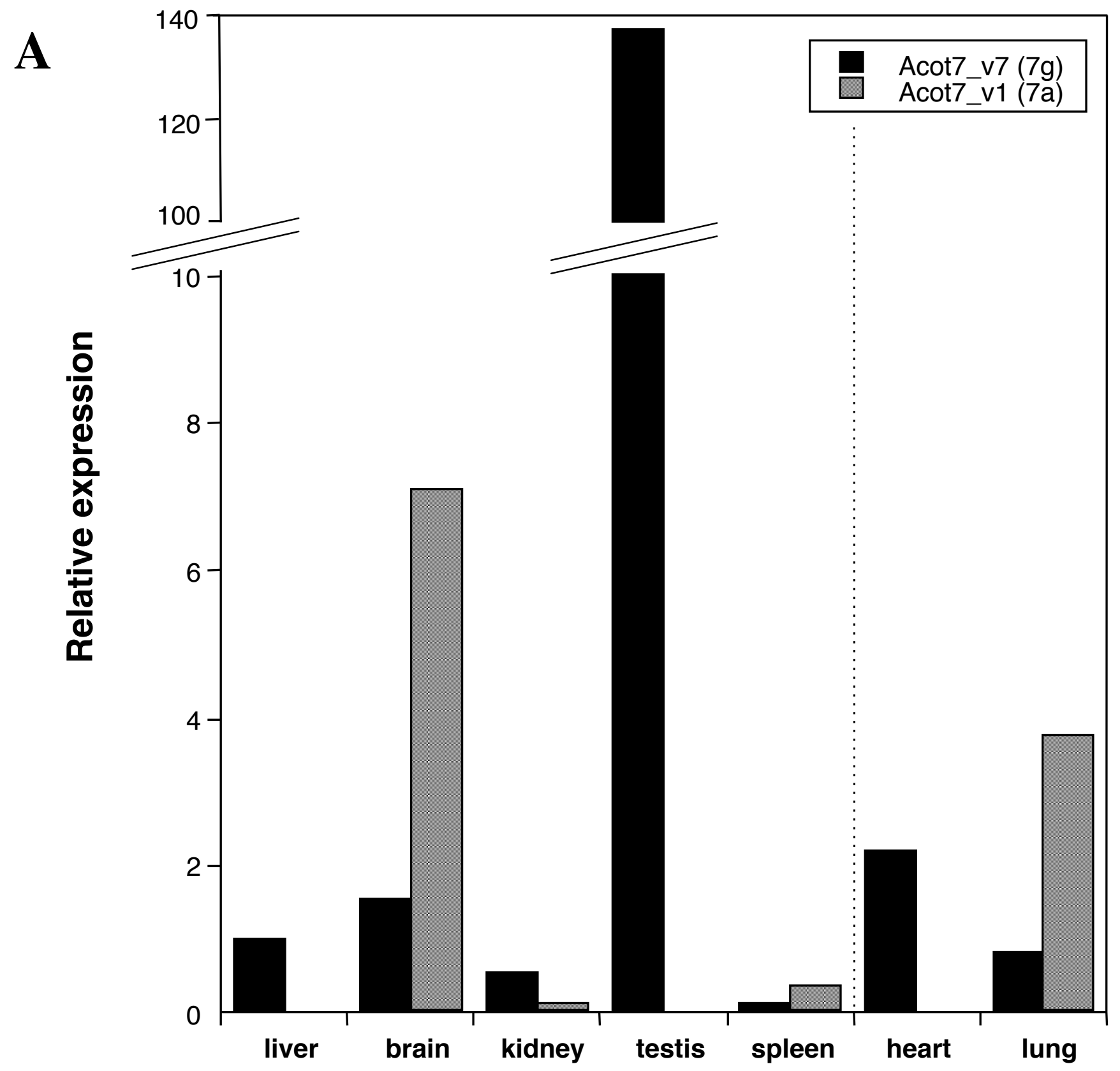


B

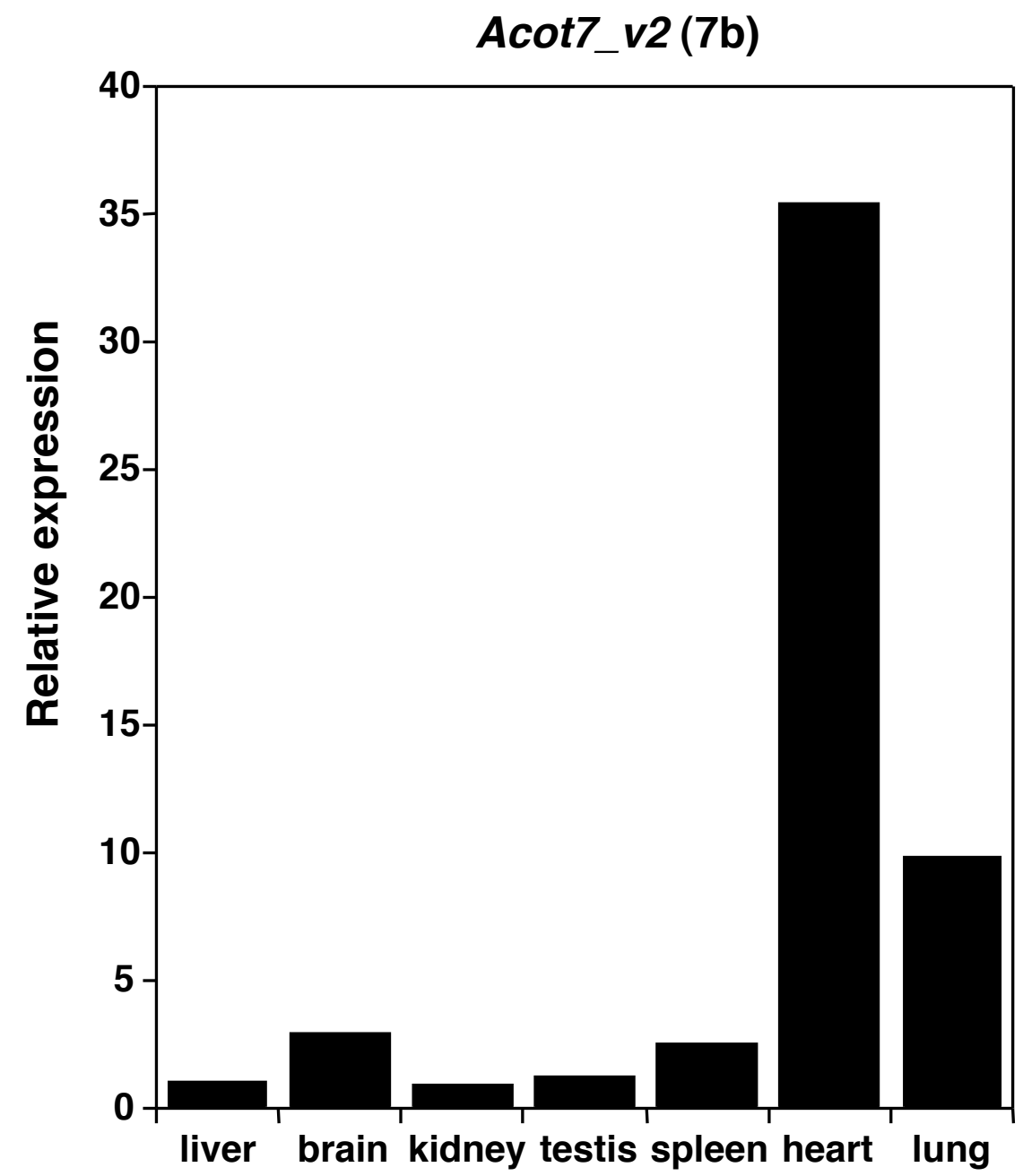

C

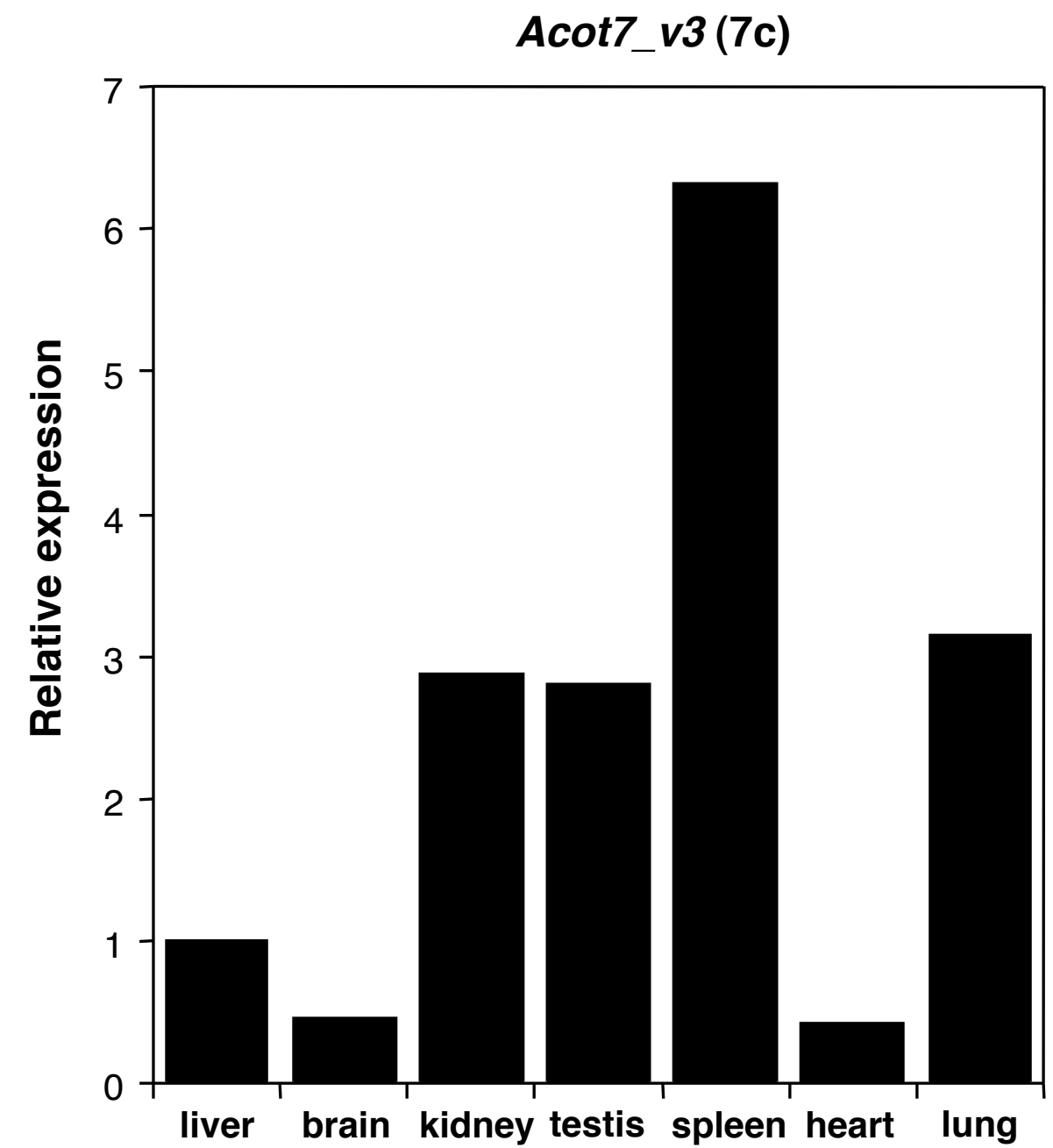


D

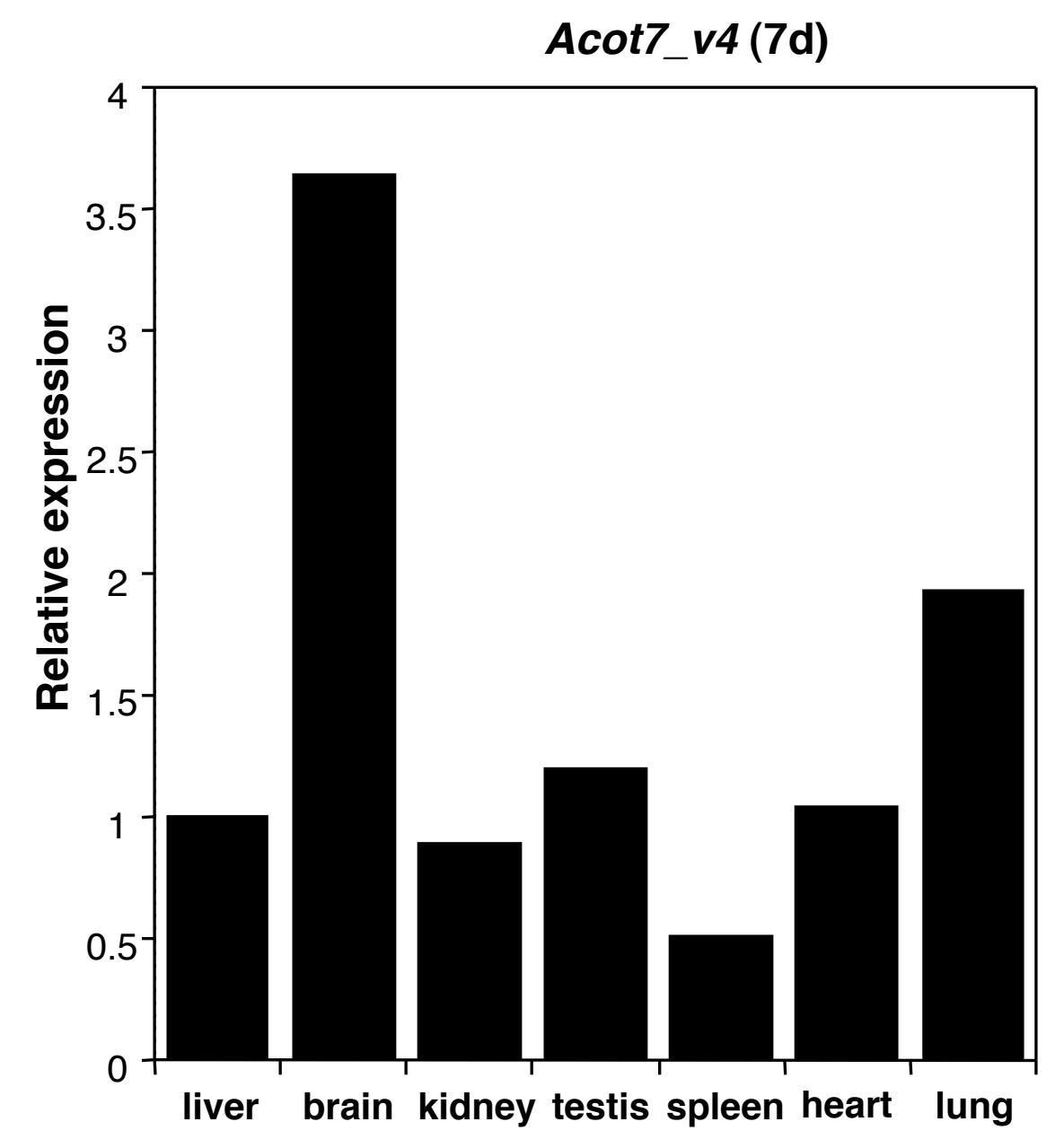

E

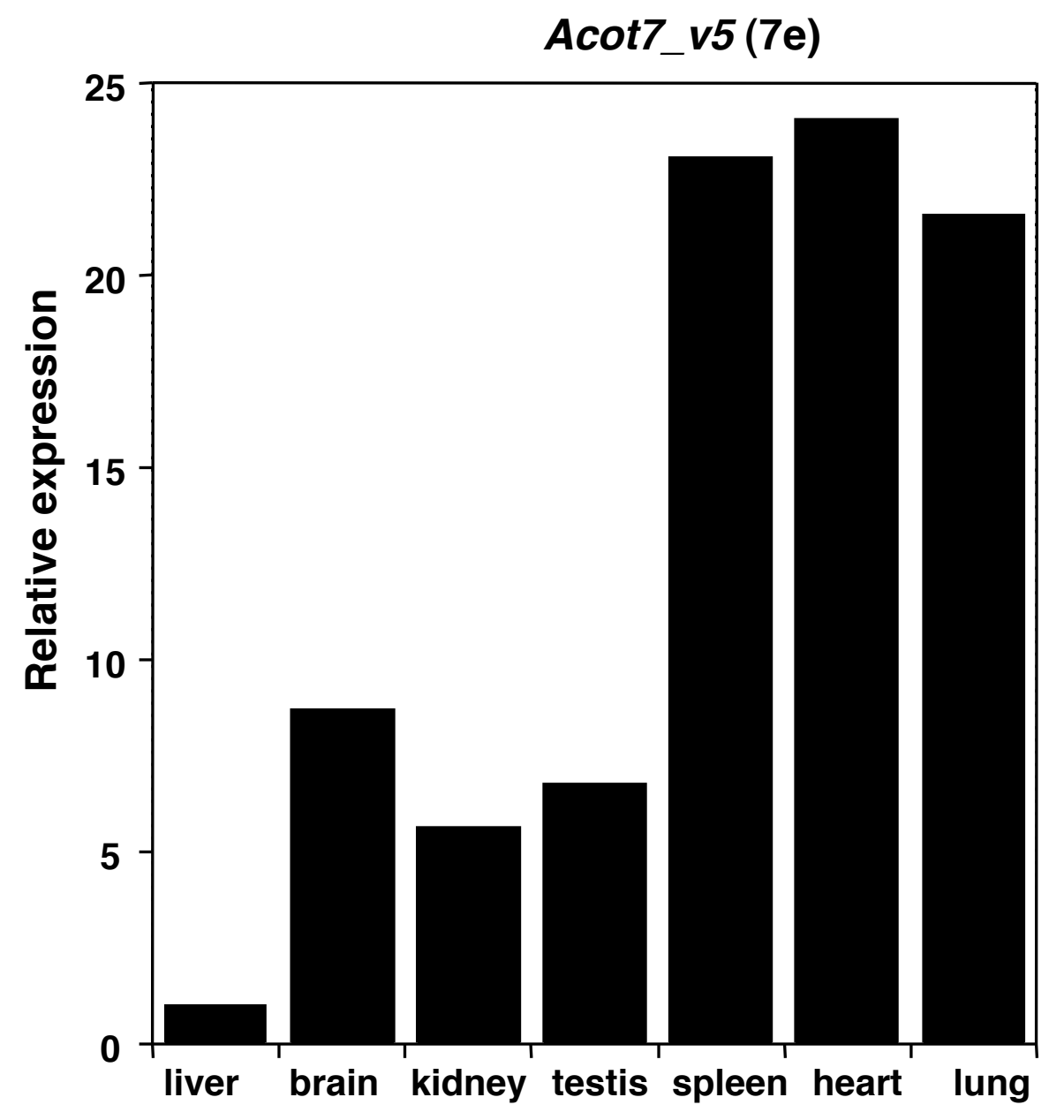


Hunt et al.

Fig 4

A

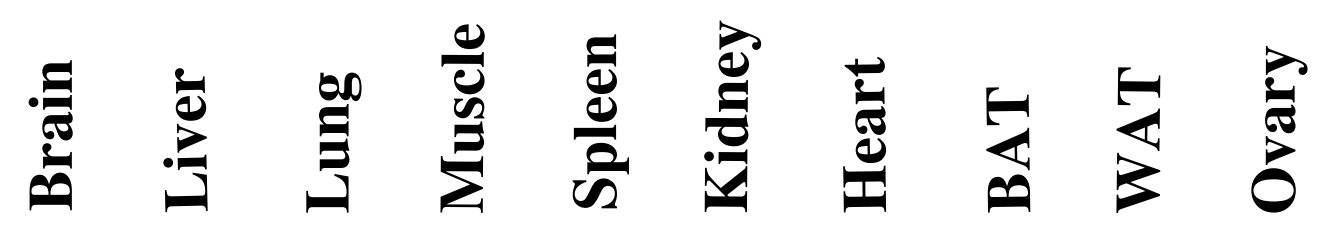

$\longleftarrow \quad 2 \mathrm{~kb}$

B

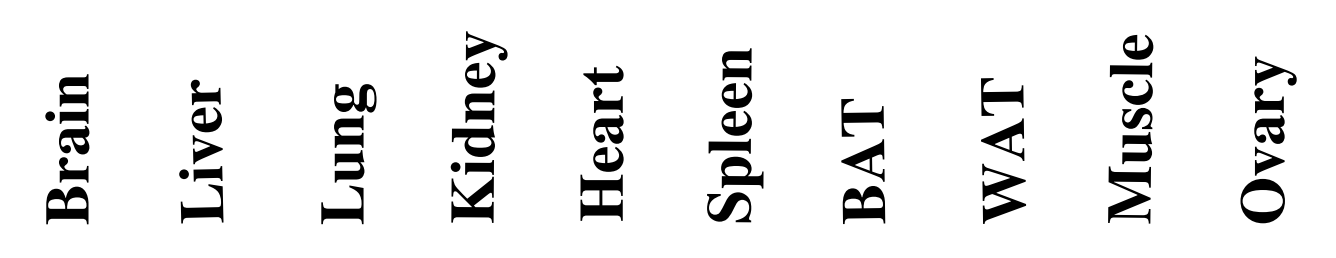

$\longleftarrow \quad 50$ kDa

$\longleftarrow \quad 43$ kDa 
Hunt et al.

Fig 5

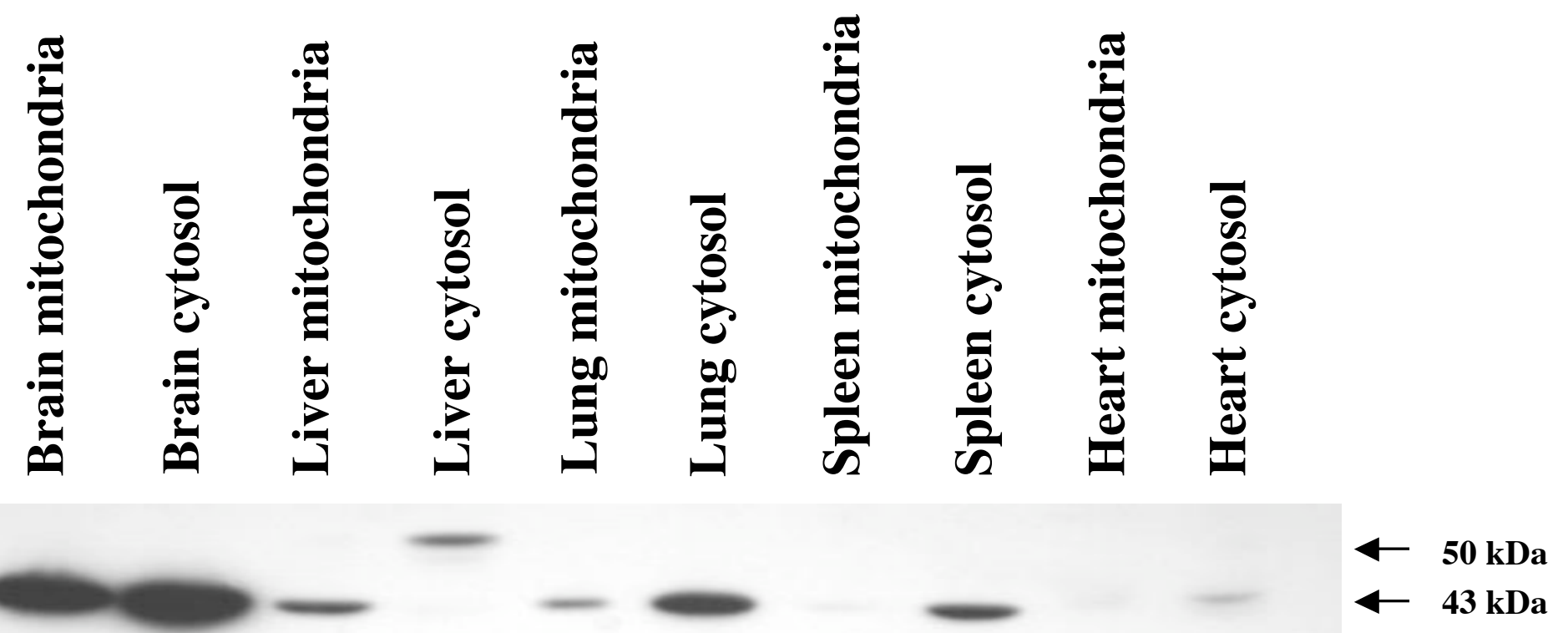


Hunt et al.

Fig 6

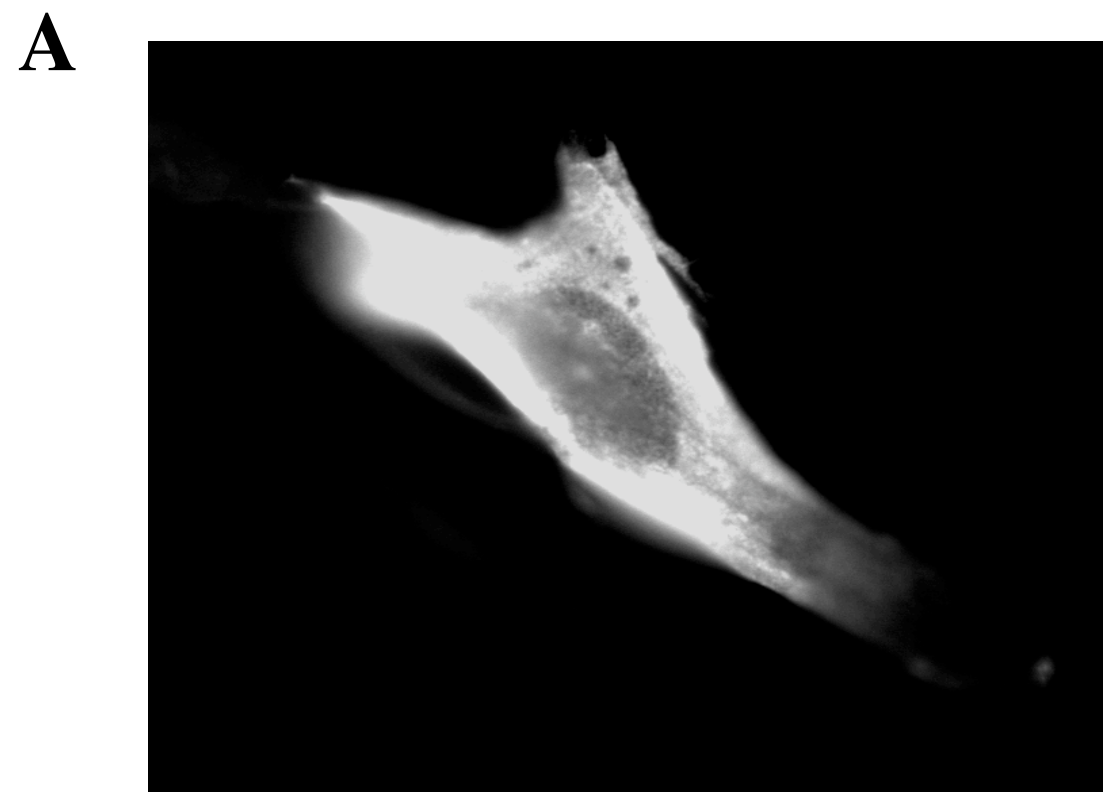

C

B
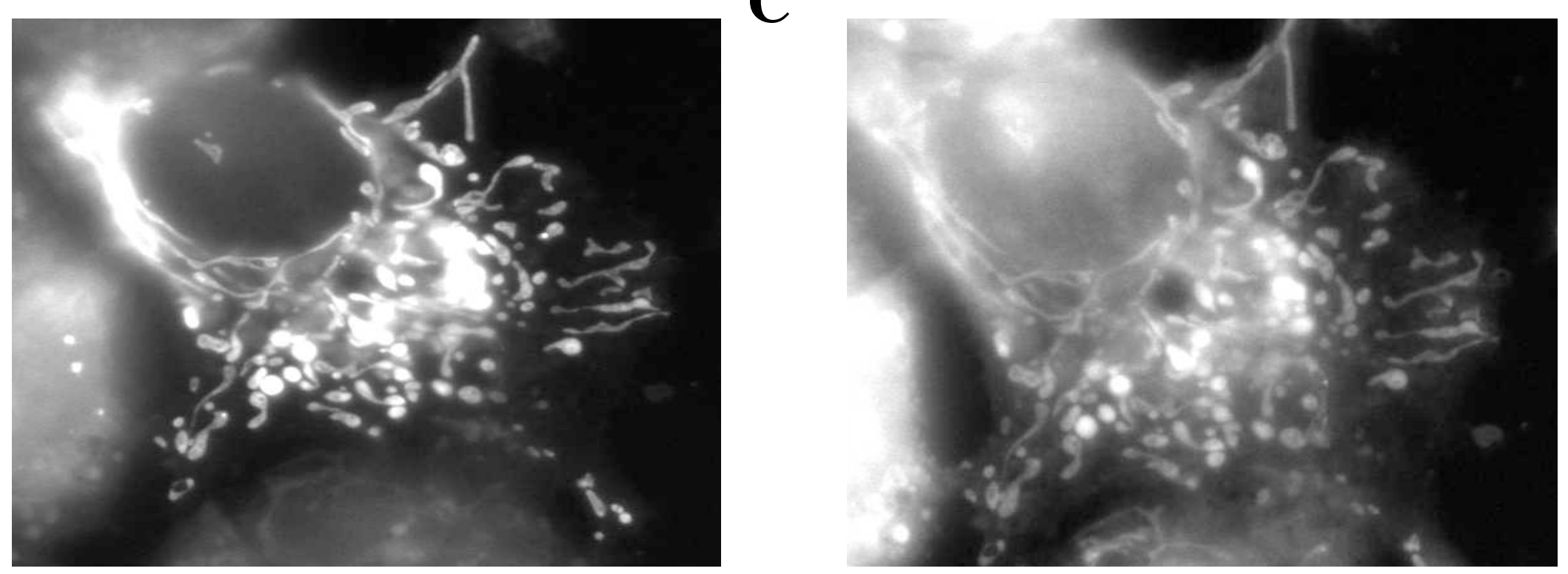
Hunt et al.

Fig 7

A

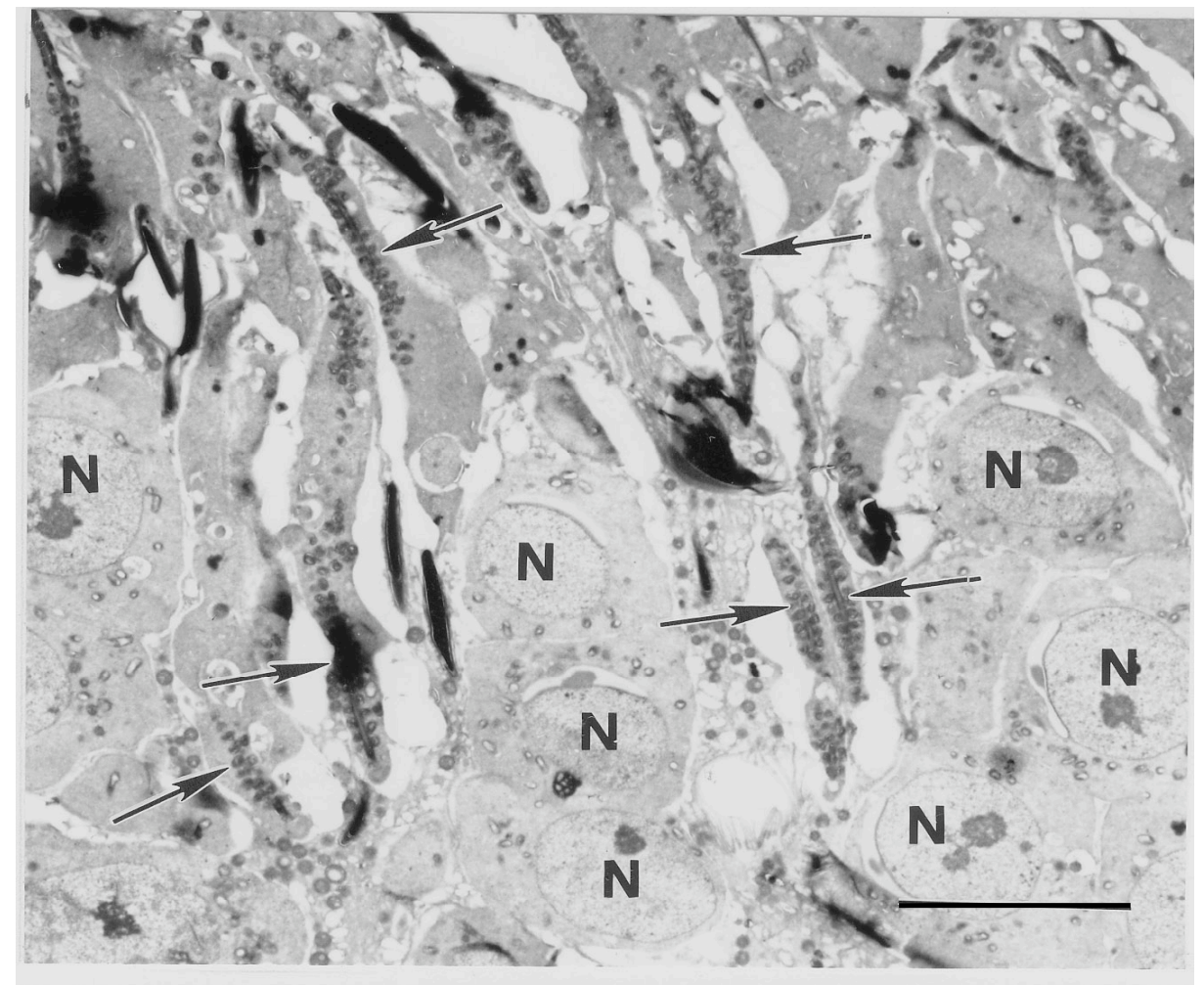

B

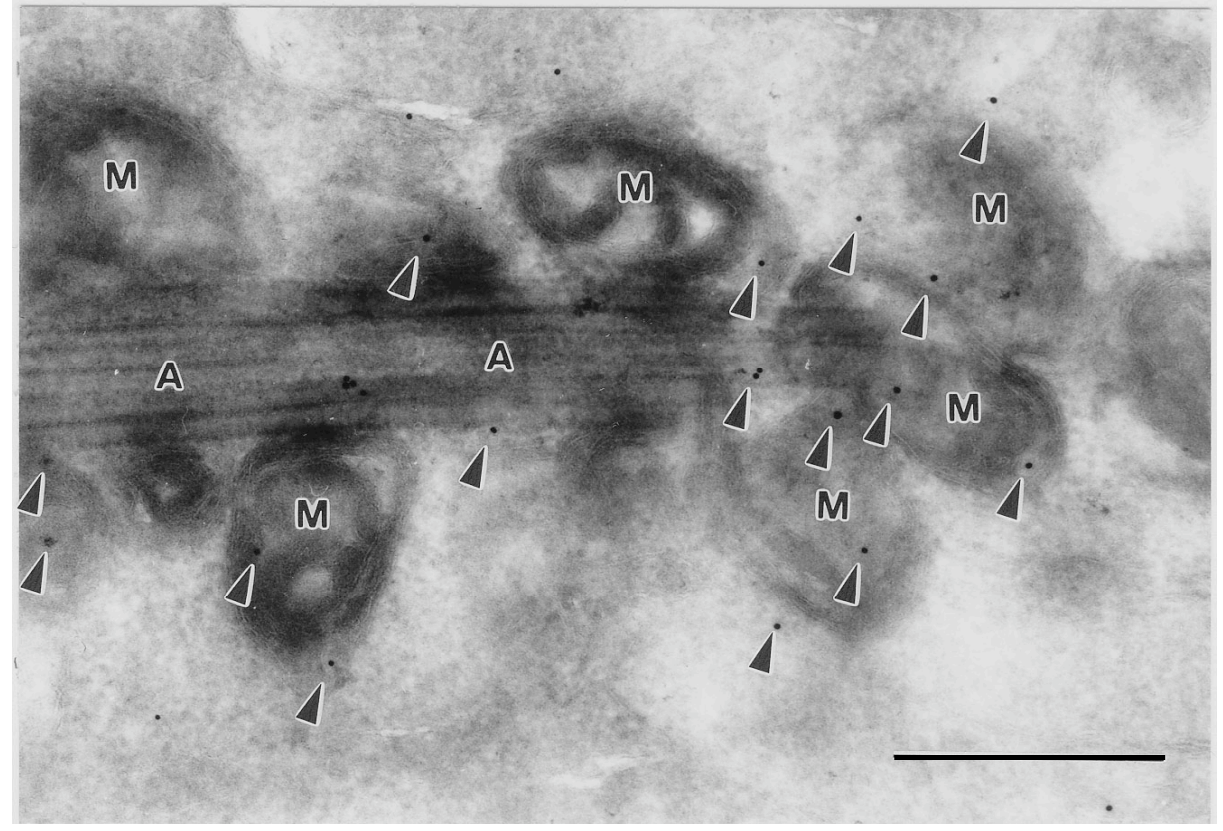

